\title{
Cabine Pets: promovendo o incentivo à adoção responsável e o engajamento da população nos cuidados de animais abandonados
}

\author{
Tamires Ariane S. Sousa \\ Universidade Federal do Ceará \\ Russas, CE, Brasil \\ eng.soft.tamires@alu.ufc.br
Gabriel Fonseca de O. Júnior
Universidade Federal do Ceará
Russas, CE, Brasil
gabrieljunior@alu.ufc.br

\author{
Valéria Maria da S. Pinheiro \\ Universidade Federal do Ceará \\ Russas, CE, Brasil \\ valeriam.soft@alu.ufc.br \\ Anna Beatriz Marques ${ }^{\dagger}$
Universidade Federal do Ceará
Russas, CE, Brasil
beatriz.marques@ufc.br
}

\begin{abstract}
RESUMO
O abandono de animais é um problema que afeta diversas áreas como saúde, meio ambiente e trânsito. Além disso, os animais abandonados ficam propícios a doenças, fome e maus tratos. Torna-se importante conscientizar a população sobre as consequências do abandono de animais, bem como incentivar sua maior participação nos cuidados e adoção de animais abandonados. Por meio da adoção da metodologia de Design Thinking, uma solução tecnológica denominada Cabine Pets foi idealizada. Este artigo apresenta o processo de design conduzido e os principais artefatos gerados. Uma solução tecnológica é descrita, consistindo na instalação de cabines com comedouros que são acionados por meio de doações em moedas, liberando ração e água para os animais e essa doação pode ser registrada em um aplicativo móvel. Por meio desse aplicativo também é possível realizar outras doações e visualizar informações sobre animais para adoção e postagens de conscientização que são realizadas por ONGs e profissionais da saúde, como médicos veterinários.
\end{abstract}

\section{PALAVRAS-CHAVE}

Animais abandonados, adoção responsável, ONGs.

\section{Introdução}

O convívio com animais de estimação proporciona benefícios psicológicos, sociais e fisiológicos ao ser humano [1]. A

\footnotetext{
$\dagger$ Líder da equipe
}

Permission to reproduce or distribute, in whole or in part, material extracted from this work, verbatim, adapted or remixed, as well as the creation or production from the content of such work, is granted without fee for non-commercial use, provided that the original work is properly credited. IHC 2019 - Competição de Design, Outubro 21-25, 2019, Vitória, Brasil. In Anais Estendidos do XVIII Simpósio Brasileiro sobre Fatores Humanos em Sistemas Computacionais. Porto Alegre: SBC. (c) 2019 by the author(s), in accordance with the terms of the Creative Commons Attribution-NonCommercial 4.0 International Public License (CC BY-NC 4.0).
Declaração Universal dos Direitos dos Animais [2] afirma que todo animal tem direito ao respeito, ao cuidado e proteção do homem. Porém, muitos animais domésticos acabam sendo abandonados nos centros urbanos [3]. O abandono pode ocorrer por falta de conscientização e entendimento das necessidades de um animal doméstico, ocasionando o sofrimento do animal [4].

Quando se abandona animais, estes ficam propícios a se reproduzirem sem controle e supervisão [6][7], ficando sujeitos a maus tratos, fome e doenças [1]. Outras consequências do abandono de animais são o risco de transmissão de doenças, possíveis agressões à população e acidentes de trânsitos que podem resultar em óbitos de animais e seres humanos [1]. Embora a Lei $\mathrm{N}^{\circ} 13.426 / 2017$ tenha criado a política de controle de natalidade de cães e gatos [8], em muitas cidades ainda não existem iniciativas governamentais com o objetivo de chamar a atenção sobre esse problema e suas consequências, desta forma são criadas ONGs (Organizações Não Governamentais) com o propósito de amenizar o problema e fornecer apoio aos animais abandonados com o engajamento da população [1].

Com isso, a educação sobre a guarda responsável e a conscientização sobre o problema do abandono é necessária, de forma a alcançar toda a população. Existem soluções tecnológicas para incentivar a adoção de animais abandonados (Adota Aqui! ${ }^{1}$, MeAuDote $^{2}$, appegada ${ }^{3}$ ). Contudo, neste trabalho, pensou-se em uma solução tecnológica denominada Cabine Pets que vai além de incentivar a adoção responsável. Por meio da cabine, espera-se engajar pessoas que podem não ter condições de adotar, mas desejam colaborar junto à ONGs nos cuidados de animais abandonados, realizando doações em moedas na própria cabine, liberando ração e água para os animais abandonados. De forma a complementar a cabine, um aplicativo móvel foi desenvolvido para promover uma maior interação entre os envolvidos na causa. No aplicativo será possível também realizar doações, conhecer

\footnotetext{
${ }^{3}$ https://play.google.com/store/apps/details?id=com.appegada
}

${ }^{1}$ https://play.google.com/store/apps/details?id=com.yamauchi.adotaaqui

${ }^{2}$ https://play.google.com/store/apps/details?id=br.com.meuadote 
animais que estão para adoção e verificar postagens relacionados ao tema.

\section{Metodologia}

Para o design desta solução, adotou-se a metodologia de Design Thinking, que visa a resolução de problemas por meio de uma abordagem centrada no usuário, inovadora, colaborativa e experimental [9]. A equipe adotou quatro etapas no desenvolvimento da solução (Figura 1).

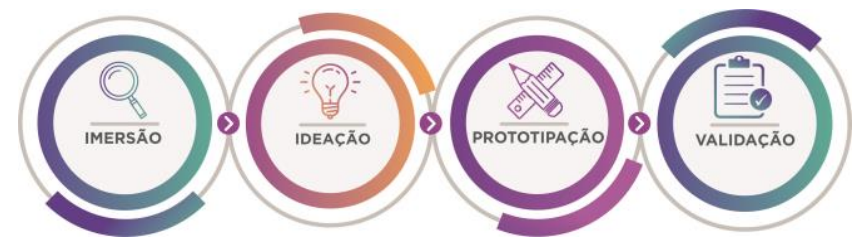

Figura 1: Etapas do Design Thinking

\subsection{Imersão}

A imersão iniciou com a realização de um brainstorming entre a equipe, com o objetivo de identificar o público-alvo, as funcionalidades e as tecnologias que pudessem viabilizar uma solução adequada. Os resultados do brainstorming são apresentados na Figura 2.

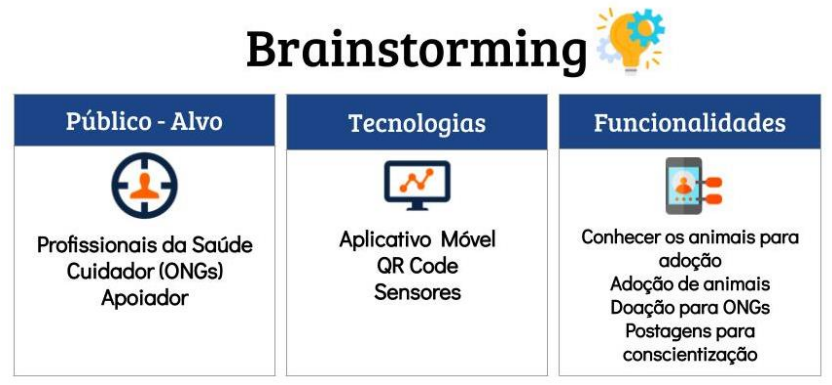

Figura 2: Resultado do brainstorming inicial

Após a análise e síntese das informações, foram elaborados roteiros e realizadas entrevistas direcionadas a três perfis específicos: veterinários (profissional responsável por cuidar da saúde do animal), apoiadores (pessoas que ajudam os animais de forma informal) e cuidadores (pessoas ligadas à ONGs ou instituições de proteção animal). Sete voluntários participaram das entrevistas, entre eles um veterinário, dois cuidadores e quatro apoiadores.

Em geral as perguntas foram relacionadas ao tema de abandono de animais e adoção. De forma específica, direcionadas a cada perfil, foram realizadas perguntas sobre (i) saúde animal e relação com a saúde humana, no caso de profissional de saúde; (ii) sobre o funcionamento de abrigos, cuidados com animais abandonados e adoção de animais, para os cuidadores (ONGs); (iii) sobre convívio com os animais de estimação e a motivação para o engajamento com a causa, para os apoiadores. Cinco entrevistas

foram realizadas presencialmente e duas entrevistas foram realizadas de forma online.

Desta forma, as entrevistas possibilitaram a caracterização de diferentes visões relacionadas à problemática (Tabela 1).

Tabela 1. Comentários dos entrevistados

Perfis

\begin{tabular}{|l|l|}
\hline \multicolumn{1}{|c|}{$\begin{array}{l}\text { "Muitas vezes eles não veem o } \\
\text { animal como forma de um } \\
\text { benefício à saúde, eles veem o } \\
\text { animal como uma forma de } \\
\text { descarte." }\end{array}$} \\
\hline & $\begin{array}{l}\text { "É preciso informar as pessoas. } \\
\text { Muitas delas não têm } \\
\text { conhecimento sobre algumas leis. } \\
\text { Além disso é necessário } \\
\text { conscientizar as pessoas." }\end{array}$ \\
\hline & $\begin{array}{l}\text { "Pelo o fato de não ter condições } \\
\text { de abrigar todos os animais em } \\
\text { minha casa, sempre que posso } \\
\text { alimento eles na rua." }\end{array}$ \\
\hline
\end{tabular}

\subsection{Ideação}

A etapa de Ideação tem como objetivo estimular o pensamento criativo dos envolvidos e propor soluções que estejam de acordo com o contexto observado [10]. Para isso, foram realizadas pesquisas para identificar soluções existentes e tecnologias que pudessem viabilizar a proposta.

Carpanezi et al. [10] apresentam o desenvolvimento de um aplicativo que facilita a adoção de animais que estão em ONGs, mostrando resultados satisfatórios obtidos na validação do sistema. O projeto "AlimentaCão", promove a instalação de comedouros com rações para os animais de rua.

Deste modo, as informações das entrevistas e das pesquisas foram analisadas pela equipe mediante reuniões de brainstorming. Como resultado, foi proposto a Cabine Pets. Uma solução que consiste em: (1) cabines instaladas em regiões estratégicas para que a população possa realizar doações em moedas, liberando em tempo real, ração e/ou água para animais abandonados da região, além de receber materiais de conscientização sobre o abandono de animais; e (2) um aplicativo móvel onde a população poderá obter informações sobre animais para adoção, localização de cabines em sua região, postagens sobre conscientização e sua posição em um ranking obtido a partir de doações nas cabines ou pelo aplicativo. Além disso adotantes poderão manter o perfil dos animais após a adoção e médicos veterinários poderão interagir no aplicativo por meio de postagens de conscientização sobre os cuidados de animais.

\subsection{Prototipação}

Nesta etapa foram desenvolvidos os protótipos da solução (cabine e aplicativo) e suas funcionalidades. 
Cabine Pets: promovendo o incentivo à adoção responsável e o engajamento da população nos cuidados de animais abandonados

A cabine (Figura 3) possui dois metros de altura e seis lados. Externamente, pode ser personalizada de forma que torne mais fácil a identificação de seu objetivo. O lado (1) dispõe de um tablet onde o doador poderá escolher o tipo da ração (para gato ou cachorro), uma entrada de moedas e uma saída para emissão de panfletos. Nos outros quatro lados (2, 3, 5 e 6) estão posicionados os comedouros que possuem canos que despejam comida e água em recipientes posicionados nas partes inferiores.

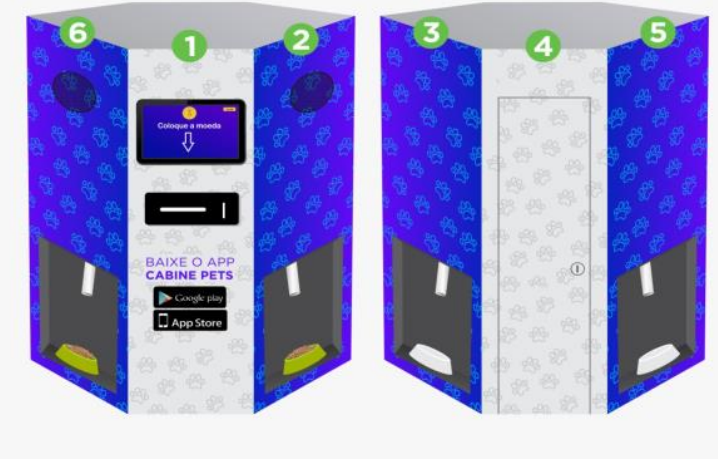

Figura 3: Protótipo da cabine

A cabine também dispõe de dois alto falantes na parte superior de duas faces ( 2 e 6). No lado 4 , há uma porta que dá acesso ao interior da cabine, permitindo sua manutenção pela ONG. Dentro da cabine, há dois reservatórios para armazenamento de rações, um reservatório para armazenamento de água, uma caixa para captar as moedas e uma caixa contendo os panfletos de conscientização.

Para alimentação da cabine, deve ser utilizada energia elétrica, bateria e conexão com a internet. Sua estrutura será composta por Metalon e placas de ACM (alumínio composto). Para controlar o funcionamento da cabine serão utilizados sensores de presença, motores e um computador. A cabine pode ser programada para emitir sons de latidos e miados como forma de chamar a atenção das pessoas que estiverem próximas.

A Figura 4 apresenta a tela inicial do protótipo do aplicativo, desenvolvido de forma complementar às funcionalidades da cabine.

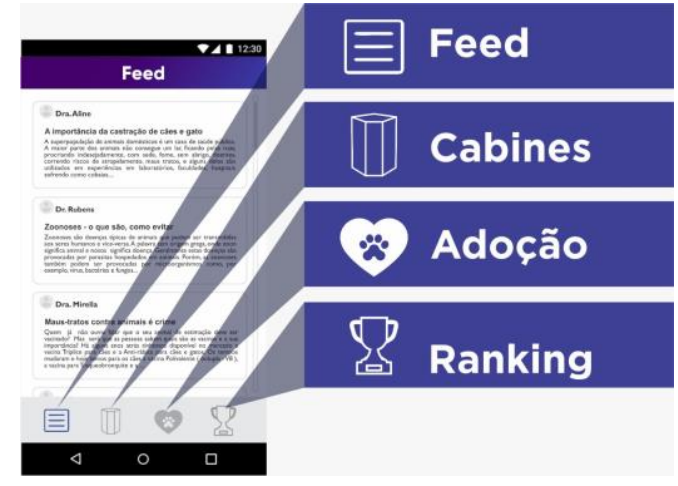

Figura 4: Protótipo do aplicativo
IHC'19, Oct 2019, Vitória, Espírito Santo-Brazil

A tela inicial terá quatro abas com as principais funcionalidades do aplicativo. A aba "Feed" mostra publicações de conscientização sobre o abandono de animais. Um mapa de localização das cabines pela cidade pode ser visualizado na aba "Cabines". A aba "Adoção" lista perfis de animais para adoção cadastrados pela ONG que mantém a cabine. O "Ranking" adota a ideia de gamificação às doações realizadas na cabine.

\subsection{Validação}

Com o objetivo de validar a solução proposta, elaborou-se um questionário para ser respondido pelos participantes da entrevista e por pessoas que possuíam o mesmo perfil dos entrevistados. O questionário era composto por quatro questões abertas, são elas: "Coisas que você mais gostou", "Coisas que você menos gostou/não entendeu”, "O que pode ser melhorado" e "Sua opinião sobre a viabilidade de implantar a Cabine Pets” (Figura 5).
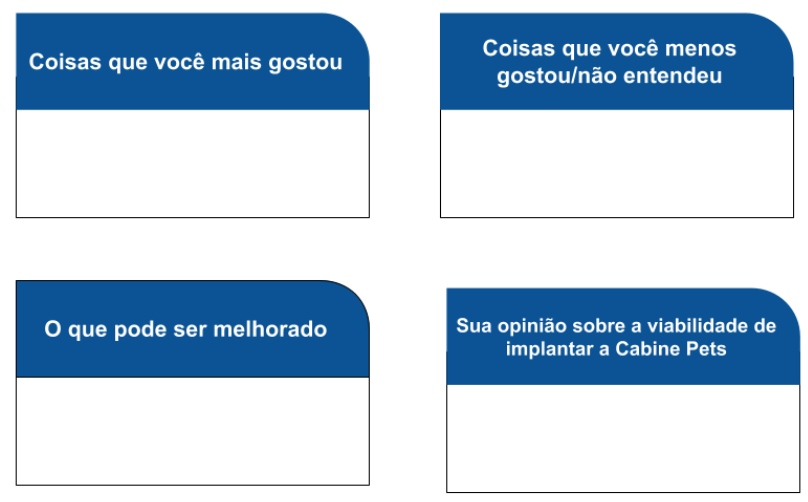

Figura 5: Questionário de validação

As respostas dos questionários indicaram percepções positivas em relação à solução proposta. Os pontos positivos que mais chamaram a atenção foram: a cabine fornecer alimentos para os animais de rua e o ranking de pontos por doações. Algumas questões foram levantadas em relação forma como a água seria mantida na cabine, o que ocorrerá caso os recipientes estejam cheios e ainda, como será feita a segurança da cabine por se tratar de doações em dinheiro. Os participantes também sugeriram fixar o recipiente de alimentação na cabine para que não haja roubo.

Outra sugestão foi as pessoas gravarem vídeos na cabine pedindo doações. Além disso, um participante indicou que o controle de natalidade dos animais poderia ser incluído na solução. Por fim, quando questionados sobre a viabilidade, um participante apontou que seria muito viável se a cabine estivesse em um abrigo de animais abandonados, outro levantamento foi de que a solução seria viável com a parceria do poder público e se era possível concretizar em relação ao custo que poderia ser muito alto.

Além do questionário, a proposta da Cabine Pets foi apresentada à ONGs locais e estas demonstraram interesse em implantá-la e mantê-la. Este feedback é de total relevância para viabilizar a solução, pois é necessário que haja uma pessoa para 
acompanhar o uso da cabine realizando atividades de reposição de água/ração, retirada de moedas, reposição de panfletos, limpeza dos comedouros para que não haja propagação de doenças entre os animais e a segurança da cabine.

\section{Justificativa}

Durante o processo de Design Thinking, observou-se a necessidade de buscar estratégias para conscientizar a população de que os animais abandonados são responsabilidades de todos. As entrevistas possibilitaram a análise do problema diante de diferentes perspectivas, enquanto que reuniões de brainstorming direcionaram as decisões de design da solução. A análise de soluções existentes mostrou que em sua grande maioria as aplicações estão voltadas apenas para adoção, com isso a proposta da Cabine Pets visa incluir os apoiadores que muitas vezes não possuem condições de adotar um animal, mas gostariam de contribuir de alguma forma com as ONGs. Com a Cabine Pets é possível engajar-se nos cuidados de animais abandonados por meio de doações de forma simples. Além disso, a ação de conscientizar a população sobre o abandono de animais e adoção responsável é feita também pela Cabine Pets, por meio do recebimento de panfletos e utilização do aplicativo móvel, onde também é possível interagir com a ONG e outros apoiadores e envolvidos na causa.

\section{Cabine Pets}

A Cabine Pets pode ser mantida por ONGs e utilizadas por qualquer apoiador da causa. Com o objetivo de conscientizar a população sobre o abandono e a posse responsável, as cabines liberam materiais de conscientização por meio de doações como forma de brinde pela doação, no entanto, também os disponibiliza de forma gratuita através das postagens no aplicativo, enquanto que os comedouros e o ranking buscam envolver apoiadores nos cuidados dos animais abandonados. Além dos informativos da cabine, o aplicativo dispõe uma área para apresentar animais que buscam por um lar, possibilitando que interessados em adotar solicitem adoções e cuidadores verifiquem através do preenchimento do questionário se estes adotantes estão aptos a receberem os animais de forma responsável. Com isso, é possível dar mais visibilidade às ações das ONGs e assim, motivar cada vez mais pessoas a abraçarem a causa de animais abandonados.

A Figura 6 apresenta a interação entre usuários, cabine e aplicativo. A interação com a cabine inicia quando ao depositar uma moeda, o apoiador recebe um panfleto de conscientização a respeito do abandono de animais e por meio do tablet, escolhe o que deseja liberar nos comedouros: (i) ração para gatos, (ii) ração para cães ou (iii) água. Os sensores verificarão se os recipientes já estiverem cheios, para que não haja desperdício. Após a doação, o tablet exibe um QR Code (código) da doação, para que o apoiador possa se cadastrar e registrar sua doação no aplicativo, somando pontos no ranking de doadores. Para isso é necessário que as ONGs realizem manutenção nas Cabines realizando limpeza e reabastecendo os reservatórios de água e ração. Além disso as ONGs podem interagir por meio do aplicativo cadastrando animais disponíveis para adoção e analisando as solicitações de adoções, assim como os profissionais da saúde que interagem no aplicativo por meio de postagens de conscientização e saúde animal.

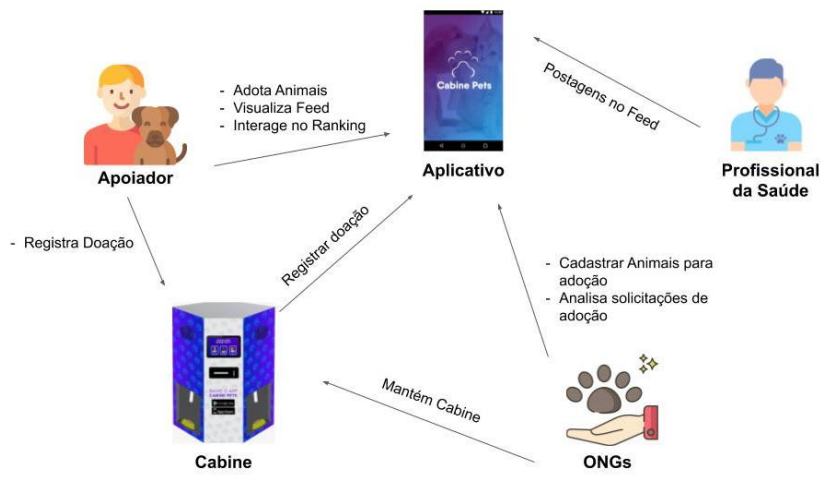

Figura 6: Interação entre usuários, cabine e aplicativo

\subsection{Cenário de uso}

Ana tem 40 anos, gosta muito de animais e sempre os alimenta na calçada de casa. Sua vizinha, Júlia, não se importa muito com essa situação. Certo dia, Ana foi a um evento na praça de sua cidade com Júlia, quando escutou um miado, mas não via nenhum gato próximo. Mais à frente visualizou uma Cabine Pets rodeada de pessoas, logo sentiu curiosidade em saber do que se tratava. Ana leu as informações da cabine, inseriu uma moeda e imediatamente recebeu um panfleto com uma notícia sobre a situação dos animais abandonados na cidade e compartilhou com sua vizinha. Depois, escolheu liberar ração para gatos e logo um gatinho se aproximou para se alimentar. Ana logo criou sua conta no aplicativo para registrar sua doação. Júlia também utilizou a Cabine Pets realizando uma doação e liberando água e ração para outros gatos. Após utilizar o aplicativo e ler as notícias postadas, a vizinha de Ana ficou muito sensibilizada com as informações sobre o abandono de animas e os impactos do abandono na sociedade como um todo e passou a utilizar o aplicativo com mais frequência e compartilhar as pastagens. Com isso, Júlia acabou adotando dois gatos.

\section{Viabilidade}

A cabine é composta por alguns elementos que serão interligados a um computador capaz de ativar suas funcionalidades.

Para se chegar ao custo financeiro da cabine, realizou-se um orçamento de todos os materiais necessários para a construção da cabine, como arduinos, sensores, motores, bombas de água, dentre outros, bem como da mão-de-obra e hardware necessários. Os materiais que compõem a estrutura da cabine e o hardware foram pesquisados em lojas virtuais onde foram encontrados revendedores com baixo custo, já o valor da mão-de-obra foi obtida no mercado local. Com isso, a solução torna-se viável economicamente caso as ONGs que desejam implantar a Cabine Pets realizem parcerias com empresas que apoiam a causa. 
Cabine Pets: promovendo o incentivo à adoção responsável e o engajamento da população nos cuidados de animais abandonados

A disposição de ONGs em adotarem a solução, encoraja a viabilidade de concretização do projeto, já que para impulsionar os benefícios da Cabine Pets se faz necessário constantes manutenções na cabine e atualizações no aplicativo.

O link interativo do protótipo está disponível em: https://adobe.ly/2XepR9e.

O vídeo de demonstração da cabine está disponível em: https://youtu.be/vGVQPFxPdJ8.

\section{REFERÊNCIAS}

[1] A. F. M. Lima, S. P. L. Luna. (2012) Algumas causas e consequências da superpopulação canina e felina: acaso ou descaso? Revista de educação continuada em medicina veterinária e zootecnia do CRMV-SP, 10(1), 32-38.

[2] ONU. (1978). Unesco. Declaração Universal dos Direitos dos Animais. Bruxelas - Bélgica, 27 de janeiro de 1978.

[3] E. O. Pastori, L. G. de Matos. (2017). Da paixão à "ajuda animalitária”: o paradoxo do "amor incondicional" no cuidado e no abandono de animais de estimação. Caderno Eletrônico de Ciências Sociais, 3(1), 112-132.

[4] L. R. Santana, T. P. Oliveira. (2006). Guarda responsável e dignidade dos animais. Revista Brasileira de Direito Animal, 1(1), 67-105.

[5] C. Magnabosco. (2006). População domiciliada de cães e gatos no Município de São Paulo: perfil através de inquérito multicêntrico. Dissertação (Mestrado) Faculdade de Saúde Pública, Universidade de São Paulo, São Paulo, 110 p.

[6] A. M. Vieira, A. B. Almeida, C. Magnabosco, J. C. P. Ferreira, S. L. P. Luna, J. L. B. Carvalho, L. H. Gomes, N. T. Paranhos, M. L. Reichmann, R. C. Garcia, V. F. P. Nunes, V. B. Cabral. (2006). Programa de controle de populações de cães e gatos do estado de São Paulo, São Paulo. BePA Boletim Epidemiológico Paulista, 3(33), 1-139.

[7] World Health Organization. (1990). World Society for Protection of Animals Guidelines for dog population management. Genebra: WHo, WSPA, 1990. p.116.

[8] Lei $\quad \mathrm{N}^{\circ} \quad 13.426 / 2017$. (2017) Disponível em http://www.planalto.gov.br/ccivil_03/_ato2015-2018/2017/Lei/L13426.htm, acesso em 06 de Jul de 2019.

[9] Brown, T. (2008) "Design thinking”, Harvard Business, Review 86, Volume 6, p. 8-92.

[10] C. A. Carpanezi, J. M. Maria das Graças, A. Pontes. (2016). Desenvolvimento de um aplicativo mobile para doação de animais de estimação. Reverte-Revista de Estudos e Reflexões Tecnológicas da Faculdade de Indaiatuba, 14(1). 